\title{
Analysis on setting airshaft at mid-tunnel to reduce transient pressure variation
}

\author{
Yingxue WANG ${ }^{*}$, Bo GAO, Chao ZHANG, Xuzhou HE \\ School of Civil Engineering, Southwest Jiaotong University, Chengdu 610031, China
}

\begin{abstract}
Setting airshaft is one of the methods efficient to control the aerodynamic effects on a train traveling through a tunnel. By using numeral simulation, analysis is carried out on the effect of airshaft on transient pressures generated in cabin. After setting airshaft, the magnitude of pressure fluctuation in cabin is reduced nearly $40 \%$. By analyzing the role of airshaft in alleviating pressure fluctuation, a formula to determine the optimal airshaft position is deduced.
\end{abstract}

Key words: tunnel; airshaft; high-speed train; transient pressure

C 2011 JMT. All rights reserved.

\section{Introduction}

$\mathrm{W}$ hen a high-speed train passes through a tunnel, compression wave and expansion wave will be generated and transmit to and fro, resulting in microcompression wave radiation at tunnel exit and pressure fluctuation in cabin [1-3]. To deal with this situation, considerable efforts [4-8], such as improving cabin's airproof parameter, enlarging the cross section of tunnel, building hood at tunnel entrance, have been made to alleviate the aerodynamic effects in the process of railway passing through tunnel. A desirable structure for a long tunnel is in the form of two shorter tunnels connected by pressure relief ducts [9]. Besides, airshaft is generally installed to reduce pressure intensity [10-11].

To control aerodynamic effects, most studies [5-6,8, 12] focused on the micro-compression wave at tunnel exit. In fact, the pressure fluctuation in cabin will reduce the comfort and even jeopardize passengers' health; thus ameliorating the transient pressure in cabin is an important topic.

When a high speed train enters into a tunnel, the compression wave is generated ahead of the train due to the piston-like action of tunnel entry motion. The compression wave, named the micro-pressure wave, is released to the atmosphere in the form of a pulse-like wave. The compression wave also arouses pressure fluctuation in cabin, which is called transient pressure. To relieve the

Received Sep. 13, 2010; revision accepted Dec. 22, 2010

${ }^{*}$ Corresponding author. E-mail: wangyingxue72@sina.com (Y.X. WANG)

doi: $10.3969 /$ j.issn. 1005-2429.2011.02.003 intensity of the booming noise, many methods have been put forward, for instance, the installation of tunnel entrance hood, side tunnel branches, and shelters with slits linking adjacent tunnels [13]. Sealing carriage can realize the goal of reducing transient pressure and improving passengers' comfort. In practice, however, complete sealing of a train body is not possible because the air conditioning and ventilation systems are equipped on train. Thus, the large amplitude pressure variations on the train body when traveling inside tunnel can penetrate into passenger's room, often leading to ear discomfort in passengers [14-16]. This situation will be more severe at higher speeds. The passenger's ear discomfort inside train is, in general, associated with the magnitude of pressure variation, the rate of pressure variation, the direction of pressure variation, etc. [17-19]. In actual high-speed railway trains, special ventilation systems are usually adopted to alleviate the pressure variations. By using a fan blower, this ventilation system controls the rates of air flowing into and out of the train, according to the pressure variations occurring inside the train. The pressure variation is proportional to the square of the train speed [18-19]. The ventilation system may not be powerful to reduce the pressure variations as the train speed increases. In order to alleviate the pressure variation inside the train, several control methods have been investigated, including using a damper system, a continuous ventilation system, and a continuous ventilation control system [18-19]. All of these methods can control the magnitude and the rate of the pressure variation inside the train.

In addition to controlling the pressure variation, building subsidiary construction in tunnel can also lessen the intensity of the pressure variation. In this paper, we use numeral simulation method to analyze the 
compression wave transportation process in a tunnel, and compare the transient pressure variations in cabin with airshaft and without airshaft in the tunnel.

\section{Governing equations}

During the course of a high-speed train passing through a tunnel, the boundary conditions are changed with time. The dynamic meshing needs to be applied in the simulation model.

The integral form of the conservation equation for a general scalar, $\phi$, on an arbitrary control volume, $V$, with moving boundaries is written as [20]

$$
\begin{aligned}
& \frac{\mathrm{d}}{\mathrm{d} t} \int_{V} \rho \phi \mathrm{d} V+\int_{\partial V} \rho \phi\left(\boldsymbol{u}-\boldsymbol{u}_{g}\right) \cdot \mathrm{d} \boldsymbol{A}= \\
& \int_{\partial V} \Gamma \nabla \phi \mathrm{d} \boldsymbol{A}+\int_{V} S_{\phi} \mathrm{d} V
\end{aligned}
$$

where $\rho$ is the fluid density; $\boldsymbol{u}$ is the flow velocity vector; $\boldsymbol{u}_{g}$ is the grid velocity of the moving mesh; $\Gamma$ is the diffusion coefficient; $S_{\phi}$ is the source term of $\phi ; \partial V$ represents the boundary of the control volume $V$.

Using a first-order backward difference formula, the time derivative term in (1) is written as

$$
\frac{\mathrm{d}}{\mathrm{d} t} \int_{V} \rho \phi \mathrm{d} V=\frac{(\rho \phi V)^{n+1}-(\rho \phi V)^{n}}{\Delta t}
$$

where $n$ and $n+1$ denote the respective quantity at the current and next time level. The $(n+1)$ th time level volume $V^{n+1}$ is computed from

$$
V^{n+1}=V^{n}+\frac{\mathrm{d} V}{\mathrm{~d} t} \Delta t
$$

where $\mathrm{d} V / \mathrm{d} t$ is the derivative of the control volume with respect to time. In order to satisfy the grid conservation law, $\mathrm{d} V / \mathrm{d} t$ is computed from

$$
\frac{\mathrm{d} V}{\mathrm{~d} t}=\int_{\partial V} \boldsymbol{u}_{g} \cdot \mathrm{d} \boldsymbol{A}=\sum_{j}^{n_{f}} \boldsymbol{u}_{g, j} \cdot \boldsymbol{A}_{j},
$$

where $n_{f}$ is the number of faces on the control volume and $\boldsymbol{A}_{j}$ is the $j$ face area vector. The dot product $\boldsymbol{u}_{g, j} \cdot \boldsymbol{A}_{j}$ on each control volume face is calculated by

$$
\boldsymbol{u}_{g, j} \cdot \boldsymbol{A}_{j}=\frac{\delta V_{j}}{\Delta t},
$$

where $\delta V_{j}$ is the volume swept out by the control volume face $j$ over the time step $\Delta t$.

Here, we chose the large eddy simulation model (LES) and pressure-far-field boundary conditions to model a free-stream condition at sites far away from tunnel entrance and exit. The transmission medium is assumed to be ideal gas.

\section{Airshaft effects}

\subsection{Calculation parameters}

The parameters of the railway, the tunnel and the airshaft are shown in Table 1. To analyze the effects of the shaft area on peak pressure at train body, the calculation results under different shaft open ratios will be given. The grid mesh at the tunnel entrance and train head is shown in Fig. 1.

At the initial time, the train is $100 \mathrm{~m}$ away from tunnel entrance. Along the tunnel, three test points are selected to be respectively 150,350 , and $500 \mathrm{~m}$ away from the tunnel entrance (the pressures at these points are denoted by $P_{150}, P_{350}$, and $\left.P_{500}\right)$. The pressure at the cabin surface is monitored in order to show the pressure fluctuations in the cabin.

\subsection{Calculation results}

Without airshaft, the transport of the compression

\begin{tabular}{|c|c|c|c|c|c|c|c|}
\hline \multirow[b]{2}{*}{ Condition } & \multirow{2}{*}{$\begin{array}{c}\text { Tunnel } \\
\text { length } L_{\mathrm{T}}(\mathrm{m})\end{array}$} & \multirow{2}{*}{$\begin{array}{c}\text { Tunnel } \\
\text { area } A_{\mathrm{T}}\left(\mathrm{m}^{2}\right)\end{array}$} & \multicolumn{3}{|c|}{ Carriage parameter } & \multicolumn{2}{|c|}{ Shaft parameter } \\
\hline & & & $\begin{array}{c}\text { Speed } \\
V(\mathrm{~km} / \mathrm{h})\end{array}$ & Area $\left(\mathrm{m}^{2}\right)$ & Length (m) & Shaft position & $\begin{array}{c}\text { Open ratio } \\
(\%)\end{array}$ \\
\hline I & \multirow{3}{*}{700} & \multirow{3}{*}{65} & \multirow{3}{*}{300} & \multirow{3}{*}{12.7} & \multirow{3}{*}{50} & - & - \\
\hline II & & & & & & \multirow{2}{*}{$\begin{array}{l}200 \mathrm{~m} \text { to tunnel } \\
\text { entrance }\end{array}$} & 14 \\
\hline III & & & & & & & 25 \\
\hline
\end{tabular}
wave, the expansion wave, and pressure fluctuation at the train body are shown in Fig. 2 and Fig. 3. After setting shaft, their transport processes are shown in Fig. 4 and Fig. 5.

Table 1 Calculation parameter

Note: shaft open ratio=shaft open area/tunnel free cross-sectional area 


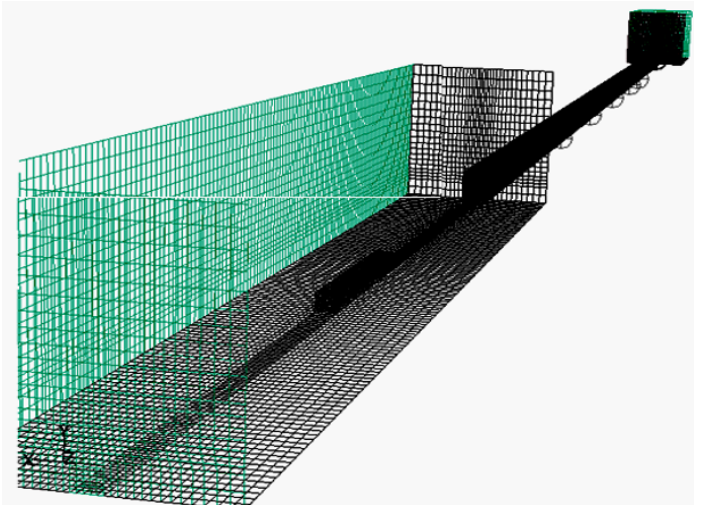

(a)

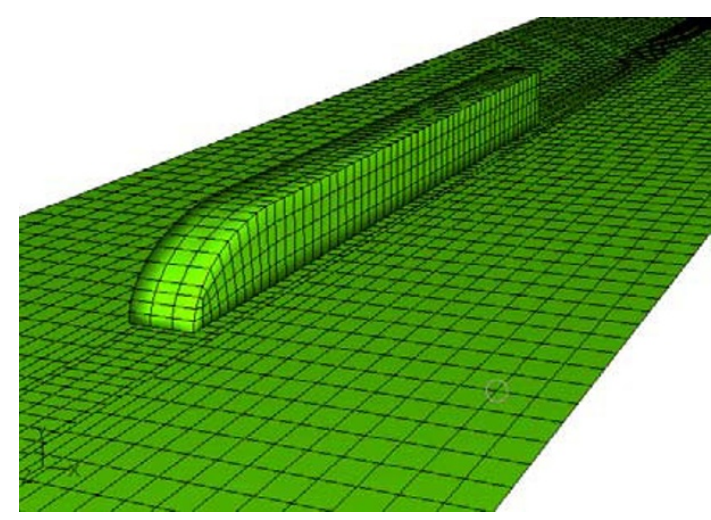

(b)

Fig. 1 The grid meshes at the tunnel entrance and train head

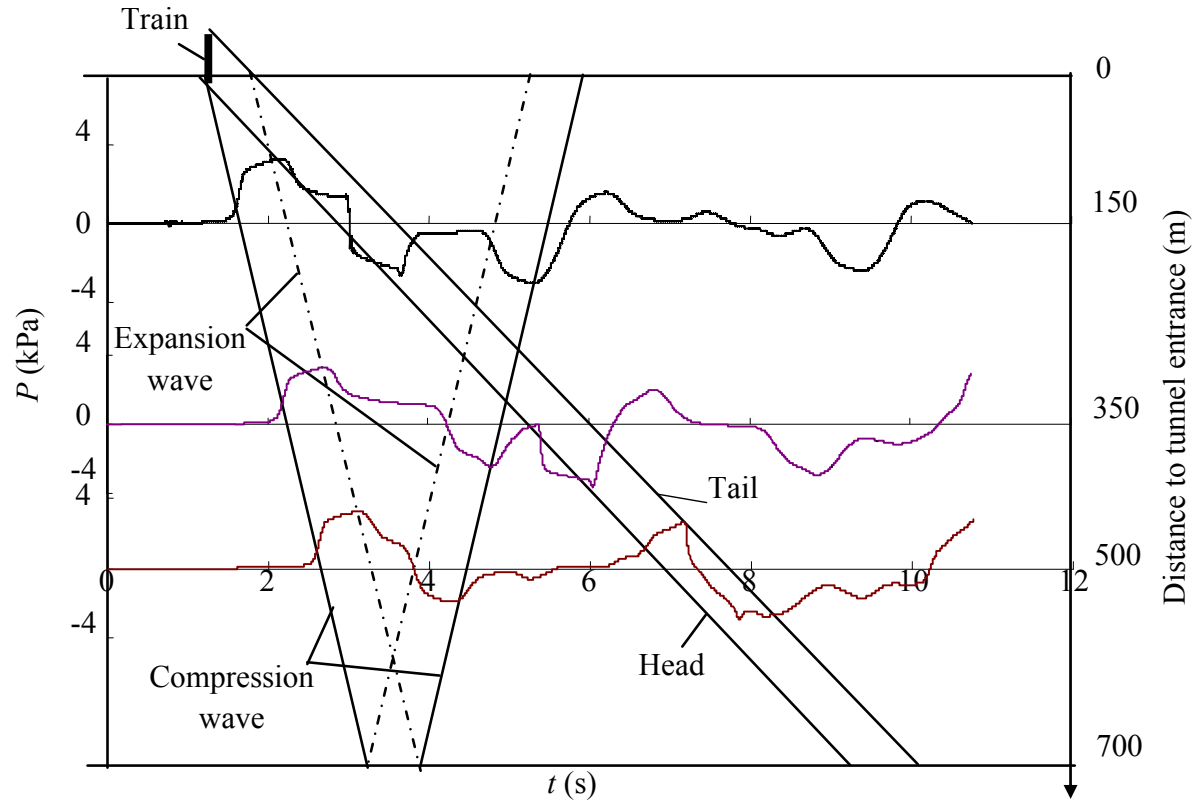

Fig. 2 Compression wave transportation process in tunnel (without shaft)

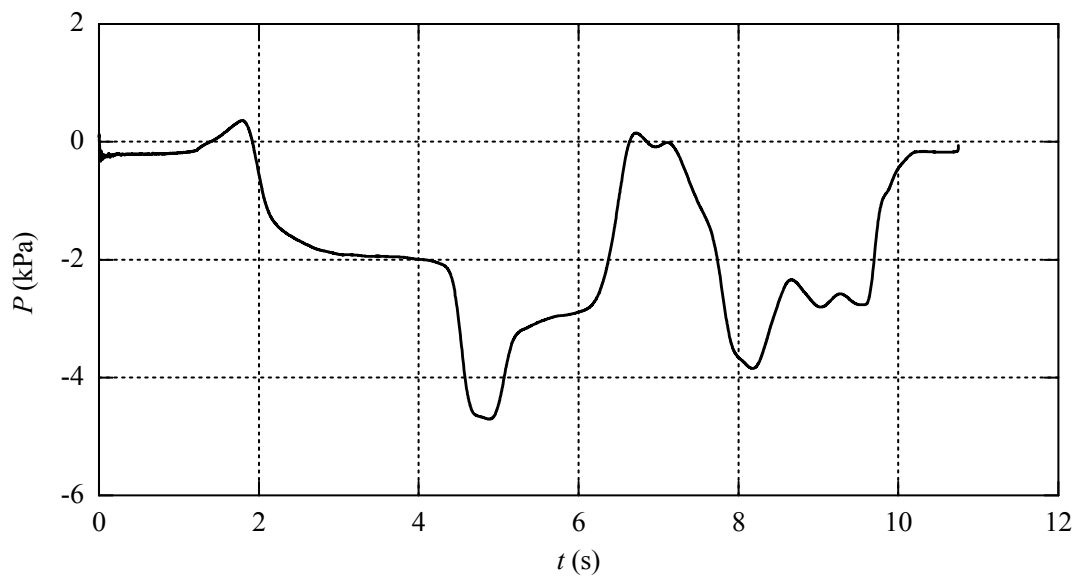

Fig. 3 Pressure fluctuation at train body (without shaft) 


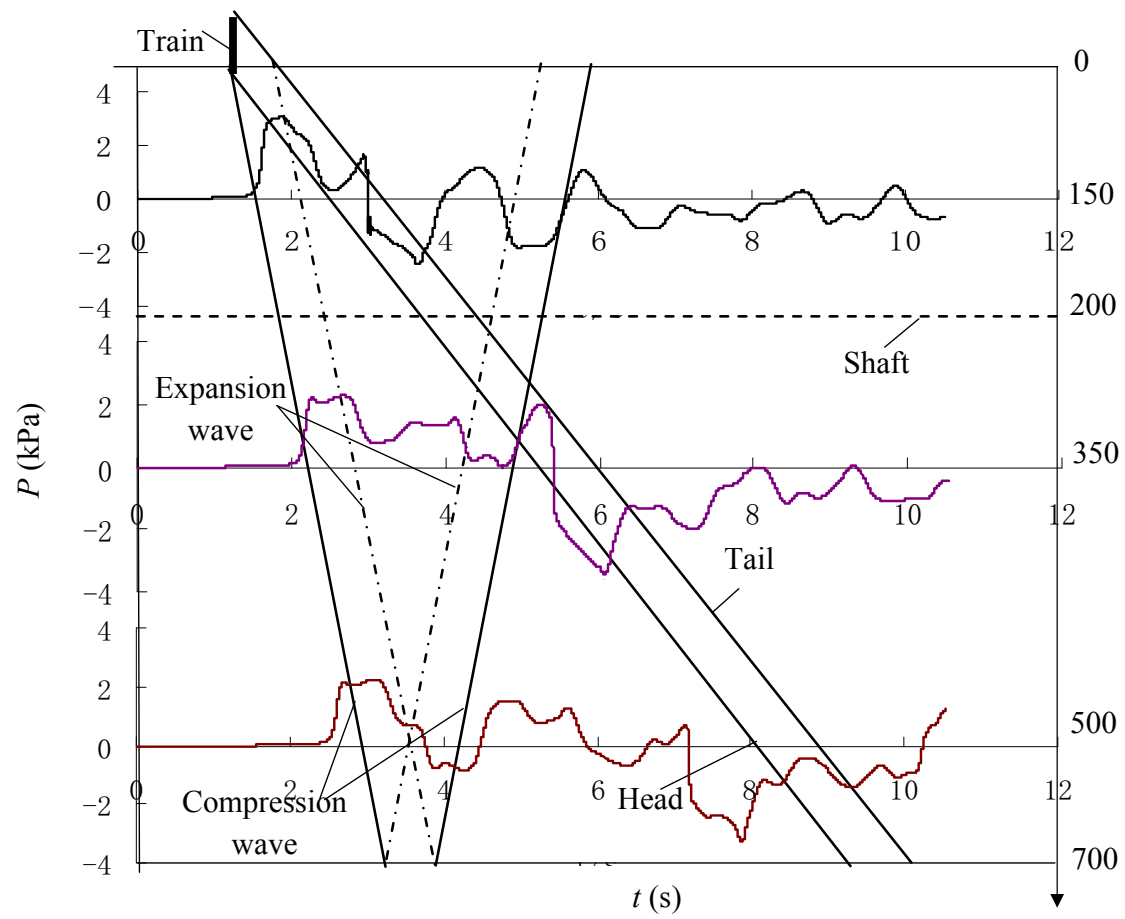

Fig. 4 Compression wave transportation process in tunnel (shaft open ratio=14\%)

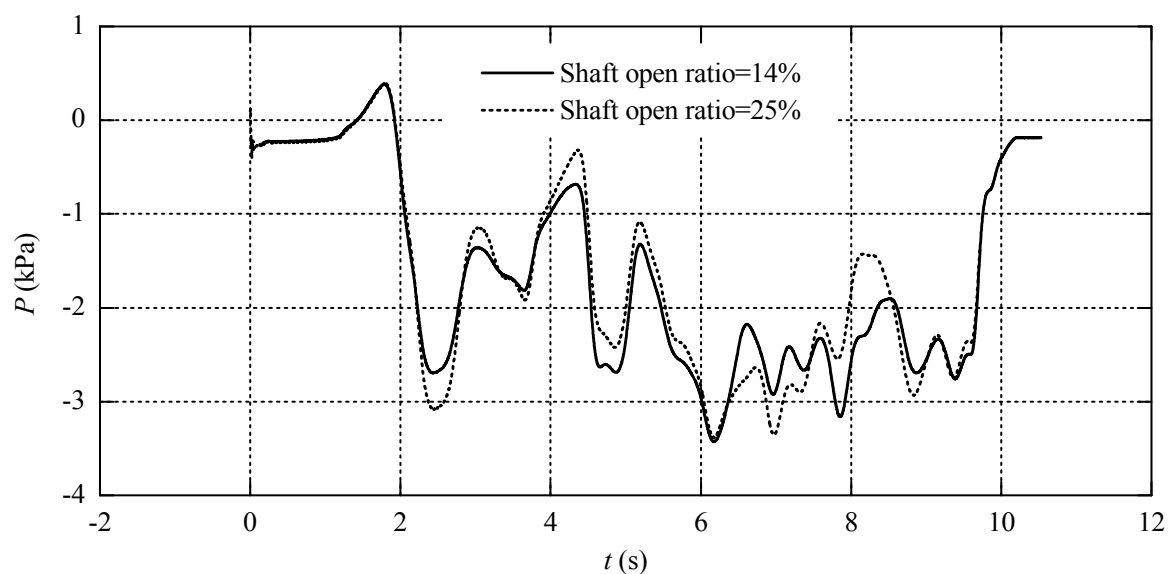

Fig. 5 Effect of shaft open ration on pressure fluctuation at train body (with shaft)

The difference of aerodynamic effects between the cases with and without airshaft is shown in Table 2.

At the train body, the first peak pressure occurs at the moment the train enters the tunnel. And the first negative peak pressure appears when the train encounters the expansion wave reflected from the compression wave at the tunnel exit. When the compression wave passes through the airshaft, energy is released and the peak value of the compression wave drops. From $P_{150}$ to $P_{350}$, the peak value of the compression changes from 3.2 to $2.1 \mathrm{kPa}$. The reduction rate is nearly $40 \%$.

As shown in Figs. 3 and 5, the compression wave reflected from the tunnel exit induces the negative fluctuation at the train body. Optimization on the airshaft position enables the expansion wave to pass through airshaft before encountering the carriage, such that the peak value of the expansion wave would be reduced. From this point of view, an expression to determine the optimal airshaft position is proposed as

$$
\frac{l_{\text {shaft }}+l_{\text {train }}}{V}>\frac{l_{\text {tunnel }}+l_{\text {tunnel }}-l_{\text {shaft }}}{c},
$$

where $l_{\text {shaft }}$ is shaft position to tunnel entrance; $l_{\text {tunnel }}$ is tunnel length; $V$ is the speed of railway; and, $c$ is the speed of sound, $c=340 \mathrm{~m} / \mathrm{s}$. In this case, the optimal airshaft position is $700 \mathrm{~m}>l_{\text {shaft }}>235 \mathrm{~m}$.

When the compression wave passes through the airshaft, the expansion wave is formed, and then encounters the train body, resulting in negative pressure in the cabin. As indicated in Fig. 2 and Fig. 4, the first nega- 
tive peak pressure in the case with shaft appears ahead of the one without shaft, and the absolute value of the peak negative pressure is larger than those at $2.3 \mathrm{~s}$ in the case of no shaft. This is because the expansion wave propagates to the tunnel entrance and encounters the train body. When the train passes through the airshaft, secondary compression wave is also excited. The expansion wave from the tunnel exit is reduced when meeting the secondary compression wave. In this way, the negative pressure on train body is lessened. In this case, ex- pansion wave hits the train before it passes through airshaft. The expansion wave creates almost the same size of the peak negative pressure as that at the airshaft. This validates that the open area at the airshaft is effective.

With the airshaft, the strength of pressure fluctuation is reduced, and the aerodynamic effects in the cabin are moderated. In the calculation example, after setting airshaft, the peak pressure at $3 \mathrm{~s}$ is reduced from 5 to $3.1 \mathrm{kPa}$. The reduction rate is nearly $40 \%$.

Table 2 Calculation result comparison

\begin{tabular}{|c|c|c|c|c|c|c|c|c|c|c|}
\hline \multirow{3}{*}{$\begin{array}{l}\text { Working } \\
\text { condition }\end{array}$} & \multicolumn{6}{|c|}{ Maximum pressure at measurement point $(\mathrm{kPa})$} & \multicolumn{2}{|c|}{$\begin{array}{l}\text { Maximum pressure } \\
\text { at train body }(\mathrm{kPa})\end{array}$} & \multicolumn{2}{|c|}{$\begin{array}{c}\text { Maximum } \\
\text { pressure transient }\end{array}$} \\
\hline & \multicolumn{2}{|c|}{$P_{150}$} & \multicolumn{2}{|c|}{$P_{350}$} & \multicolumn{2}{|c|}{$P_{500}$} & \multirow{2}{*}{ Positive } & \multirow{2}{*}{ Negative } & \multirow{2}{*}{$\mathrm{kPa} / \mathrm{s}$} & \multirow{2}{*}{$\mathrm{kPa} / 3$} \\
\hline & Positive & Negative & Positive & Negative & Positive & Negative & & & & \\
\hline Without shaft & 3.3 & -2.9 & 3.2 & -2.9 & 3.2 & -2.7 & 0.3 & -4.6 & 3.8 & 5.0 \\
\hline With shaft & 3.2 & -2.1 & 2.1 & -3.2 & 2.2 & -3.1 & 0.3 & -3.4 & 3.0 & 3.1 \\
\hline
\end{tabular}

\section{Ending remarks}

(1) The first negative peak pressure at carriage is generated when the train encounters the expansion wave, which is reflected from the compression wave at the tunnel exit.

(2) By optimizing the shaft setting, the efficiency of ameliorating aerodynamic effects is improved.

(3) When a train passes through airshaft, secondary wave will be generated. The expansion wave at the tunnel exit can be reduced when meeting the secondary compression wave.

(4) With an airshaft, the strength of pressure fluctuation is reduced, and the aerodynamic effects in cabin are moderated.

\section{Acknowledgement}

This paper is supported by the Fundamental Research Funds for the Central Universities (No.SWJTU09CX009).

\section{Reference}

[1] R.S. Raghunathan, H.D. Kim, T. Setoguchi, Aerodynamics of high-speed railway train, Progress in Aerospace Sciences, 2002, 38(6/7): 469-514.

[2] S. Mashimo, K. Iwamoto, T. Aoki, et al., Characteristics of compression wave generated by a high-speed train entering tunnel, Engineering Sciences Reports, 1997, 18(4): 297-302.

[3] S. Ozawa, Y. Moritoh, T. Maeda, et al., Investigation of pressure wave radiated from a tunnel exit, Tokyo: Railway Technical Research Institute, 1976 (in Japanese).

[4] S. Ozawa, T. Uchida, T. Maeda, Reduction of tunnel exit boom by hood at tunnel entrance, Tokyo: Railway Technical Research Institute, 1977 (in Japanese).

[5] S. Ozawa, T. Uchida, T. Maeda, Reduction of micropressure wave radiated from tunnel exit by hood at tunnel entrance, Quarterly Reports of the RTRI, 1978(19): 77-83 (in Japanese).

[6] S. Ozawa, Studies of micro-pressure wave radiated from a tunnel exit, Tokyo: Railway Technical Research Institute, 1979 (in Japanese).

[7] J.A. Fox, A.E. Vardy, The generation and alleviation of air pressure transients caused by the high speed passages of vehicles through tunnels, In: Proc. 1st ISAVVT, BHRA, 1973.

[8] M. Tastsuo, Reduction of micro-pressure wave radiated from tunnel exit by branched in tunnel, Tokyo: Railway Technical Research Institute, 1977 (in Japanese).

[9] A. Baron, M. Mossi, S. Sibilla, The alleviation of the aerodynamic drag and wave effects of high-speed trains in very long tunnels, Journal of Wind Engineering and Industrial Aerodynamics, 2001, 89(5): 365-401.

[10] A.E. Vardy, The use of air shafts for the alleviation of pressure transients in railway tunnels, In: Proc. 2nd ISAVVT, 1976.

[11] Y.X. Wang, B. Gao, K. Su, et al., Experiment research on reducing aerodynamics effect comprehensive measurement, Journal of Experiments in Fluid Mechanics, 2009, 23(1): 31-34.

[12] Y.X. Wang, B. Gao, C.Q. Zheng, et al., Microcompression wave model experiment on the high-speed train entering tunnel, Journal of Experiments in Fluid Mechanics, 2006, 20(1): 5-8.

[13] R.S. Raghunathana, H.D. Kimb, T. Setoguchic, Aerodynamics of high-speed railway train, Progress in Aero- 
space Sciences, 2002, 38(6/7): 469-514.

[14] M. Schultz, H. Sockel, Pressure transients in railway tunnels, W. Schneider, H. Troger, F. Ziegler, ed., Trends in applications of mathematics to mechanics, Harlow, 1989.

[15] N. Komatsu, F. Yamada, The reduction of the train draft pressure in passing by each other, In: Proc. World Congrence Railway Research, Tokyo: Railway Technical Research Institute, 1999.

[16] R.G. Gawthorpe, Pressure comfort criteria for rail tunnels operations, A. Haerter, ed., Aerodynamics and ventilation of vehicle tunnels, New York: Elsevier, 1991.
[17] K. Sato, M. Ikada, M. Nakagawa, Effects of pressurechanges on pain sensation of human ears, RTRI $J N R, 1989$, 3(3): 23-26 (in Japanese).

[18] Y. Zenda, Study on the ventilating system of Shinkansen vehicle by simulating the internal pressure, RTRI JNR, 1988, 2(12): 41-48 (in Japanese).

[19] M. Kobayashi, Y. Suzuki, K. Akutsu, Alleviating ear pains by controlling air pressure in ventilating system of Shinkansen car, RTRI JNR, 1990, 4(7): 16-22 (in Japanese).

[20] Fluent Inc., Fluent user's guide, http://my.fit.edu/itresour ces/manuals/fluent6.3/help/html/ug/main_pre.htm.

(Editor: Yao ZHOU) 